\title{
Android Application On Green Building Materials, Their Uses, Availability \& Certification
}

\author{
Sudheesh $\mathrm{C}^{1}$ and Prashanth $\mathrm{N}^{2}$
}

\begin{abstract}
The goal of the thesis is to spread knowledge about green building and the materials involved in construction of a green building, using android based smartphone technology. Mobile devices are used more and more frequently. We discovered that people do not use their mobile devices just for private purposes but also for work related tasks. Nowadays almost every mobile phone is running with ANDROID based OS which is much simpler and easier for common people to understand and use. This application brings you a wide range of green building materials available around the world which used for construction of Green Building. It also provide you knowledge about what the materials is, where it can be used ,why it is known as a green materials, its green attributes and more over the type of credit point which you will receive from LEED on using that particular materials. To the best of the knowledge, these functions have not been previously implemented thus this is the first attempt to do so. The goal of the project is to investigate of Green building for improving the performance, using android based smartphone technology.
\end{abstract}

Keywords - Android application, green buildings, LEED, building materials.

\section{INTRODUCTION}

\subsection{General}

It has been about two and a half years since the first Android phone has been released to the public and less than one and a half years from the last major upgrade to platform 2.x. Within this short period of time Android has managed to overtake a significant part of the global smartphone market, becoming a clear leader in year-to-year growth. With a huge and incredibly fast growing number of developers and smartphones vendors it definitely can be regarded as an interesting platform for advertisers.

Green Building(also now as green sustainable building) refers to both a structure and the using of processes that environmentally responsible and resource-efficient throughout a building's life cycle, from siting to design, construction, operation, maintenance, renovation and demolition. The Green Building practice expends and complements the classical building design concerns of economy, utility, durability and comfort.

The main objective of this work was to design and develop an application that would enabl'e users to access some of the green building materials available worldwide and to know for what purpose the material can be used directly from mobile, android running devices. The application had to fit in 
Green building construction techniques. The application had to be portable. The application had to be properly designed in terms of graphics and user interface. The application had to be fast, responsive and - at the same time - secure. The application should make a full use of the pre-implemented solutions designed by Google developers and added to the Android platform.

This paper introduces the "Green Construct application" with its basic architectural concepts, design principles and other technical aspects. All of them are presented in the context of related Google's best practices advised to Android developers. General ideas are followed each time by the outline of specific solutions implemented in the Green Construct application.

Chapter two provides background information about the Android platform itself. It focuses on fundamental components of the operating system from the point of view of application developers. Furthermore, it shows the most up-to-date smartphone market data with some statistics about the Android platform versions.

The chapter three presents an overview of Green Construct. It shows the connection of this application to other components of LEED. Moreover, it covers the most common use cases from both user's and business owner's perspectives. Some of the design patterns and user interface solutions with their implementations are presented at the end of the chapter. The main aim of the chapter is to provide answers to the following questions: what users can do with this application, how they can use it and - finally - what are the key architectural elements that take part in these actions.

\subsection{Aim}

The development of the android application is done with the help of android studio software. Protect the environmental and natural resources. Further advance techniques in structure performance. Increase in use of sustainable buildings in the future.

\subsection{Scope}

Through the help of android application we are trying to spread the knowledge about green building materials and its benefits. During next few years green building are poised to grow at $50-60 \%$ annually. The green construction cost is based on the life cycle is considerably low and it requires more professional approach.

This is application used for more people to handle the advanced construction technology in an easier way.

\section{Proposed Algorithm}

\subsection{METHODOLOGY}

The methodology of GREEN CONSTRUCT APP is divided into 4 groups, i.e.

1. Data

2. Structure

3. Coding

4. Links(android apps) 


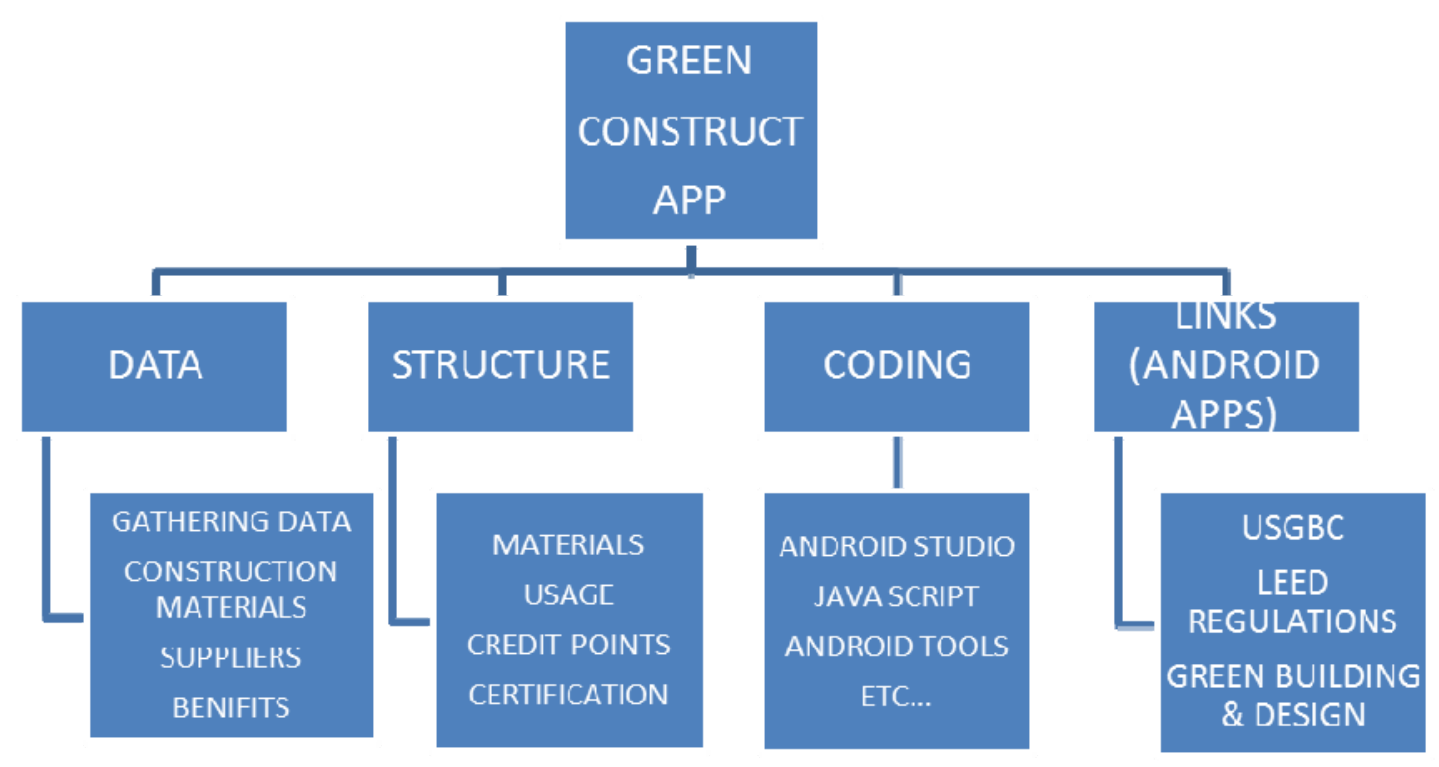

DATA: Data includes collection of green building materials available all over the world. Definition of materials, its uses, its benefits when used in construction work and much more are collected and compiled all together in a single excel sheet and saved as a CSV file. Images and its name of each and every material are also saved in order to identify each and every material.

STRUCTURE: The collected data is framed in the structure which is mentioned below. Each and every category has its own separate column and is categorized accordingly. The structure of the GREEN CONSTRUCT APP is divided into 4 groups, i.e. category, main category, sub category and various items with images and data. These 4 categories are the base in which each and material is added into the CSV file according to its category.

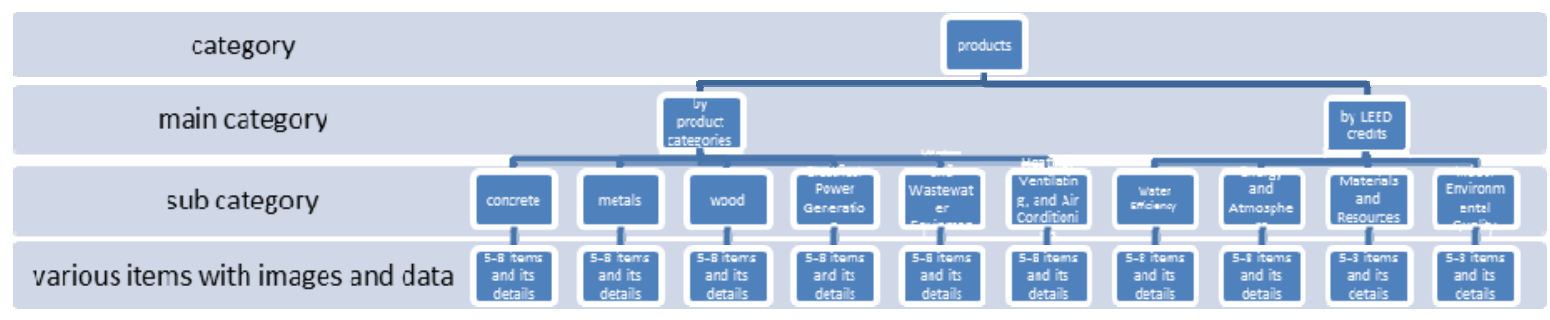

Fig

. 2.2 Data structure

CODING: The most important part of an android application is its coding. The coding for the application is provided in JAVA LANGUAGE with the help of ANDROID STUDIO SOFTWARE (Chapter 2, Android Tutorials). The coding of the application is given in such a way that it matches the categories in the above mentioned structure. Various other applications and software's are used to type the coding of the android file.

LINKS (ANDROID APPS): After the coding work is completed a separate category is made in the navigation bar for links related to other applications which are useful for construction of a green 
building. These links will be in the format of hyperlink which when clicked will direct the user to play store for downloading.

\subsection{THE ANDROID PROJECT}

Android is an open source project developed by the Open Handset Alliance and is held by Google Inc. Users can easily download new applications (also called apps) directly from their mobile devices, or by using the Play Store. One of the most appreciated aspects of Android is its openness. The source code has been revealed to the public, enabling many developers around the world not only to have better understanding of what is happening in the background of the system, but also to actively contribute to the project. It is also important to mention that all applications within the Android system are equal. Regardless to whether it is a third party application or a core system application, they all run in the same environment and potentially have the same access rights to all phone resources.

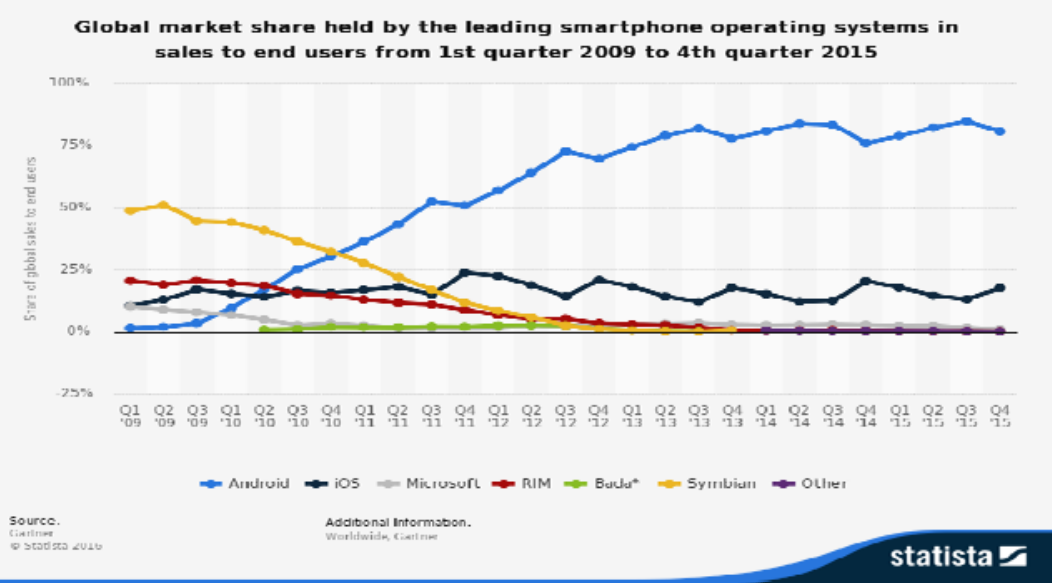

Fig. 2.3 The statistic shows the global market share held by the leading smartphone operating systems, in terms of sales to end users, since the first quarter of 2009.

\section{Main application components}

All Android applications contain zero or more of the following components:

- Activity - a single piece of user interface (UI). In a system it runs independently from other elements although users have a smooth experience of different activities appearing on the screen in a sequence. Activities usually contain some graphical elements (customized or taken from a pre-defined set) and constitute a specific action that users can perform like writing an email or selecting contact from a list.

- Service - a separate part of the application without a graphical representation (running in a background). Service itself does not start a separate thread because it runs in context of the activity or the broadcast receiver which has started it. However, it usually should use a working thread to perform some complex computation or lengthy I/O operations.

- Content Provider - a mechanism that allows applications to share data between each other or to simply persistently save some information. It is basically an interface which provides standard methods to access data like query, insert, update, delete. No specific type of data structure is imposed by the system, it can be a single file or a SQLite database. Content provider is uniquely identified by its authority and can contain many types of data objects (many tables in a database). The most common method of accessing an object is to query Content Provider with a specific content url which has a generic form of: 
content: $/ /<$ authority $>/$. . $<$ type path $>$.. $/<$ id $>/$

- Broadcast Receiver - a part of the application which responds to actions broadcasted by the system itself (dimming the screen, capturing a new photo) or by other parts of the application (the same one or not). Broadcast Receiver does not have its own graphical representation but it can initiate certain actions to keep users informed about its work. This could be done for instance by creating a notification in a status bar or updating a desktop widget.

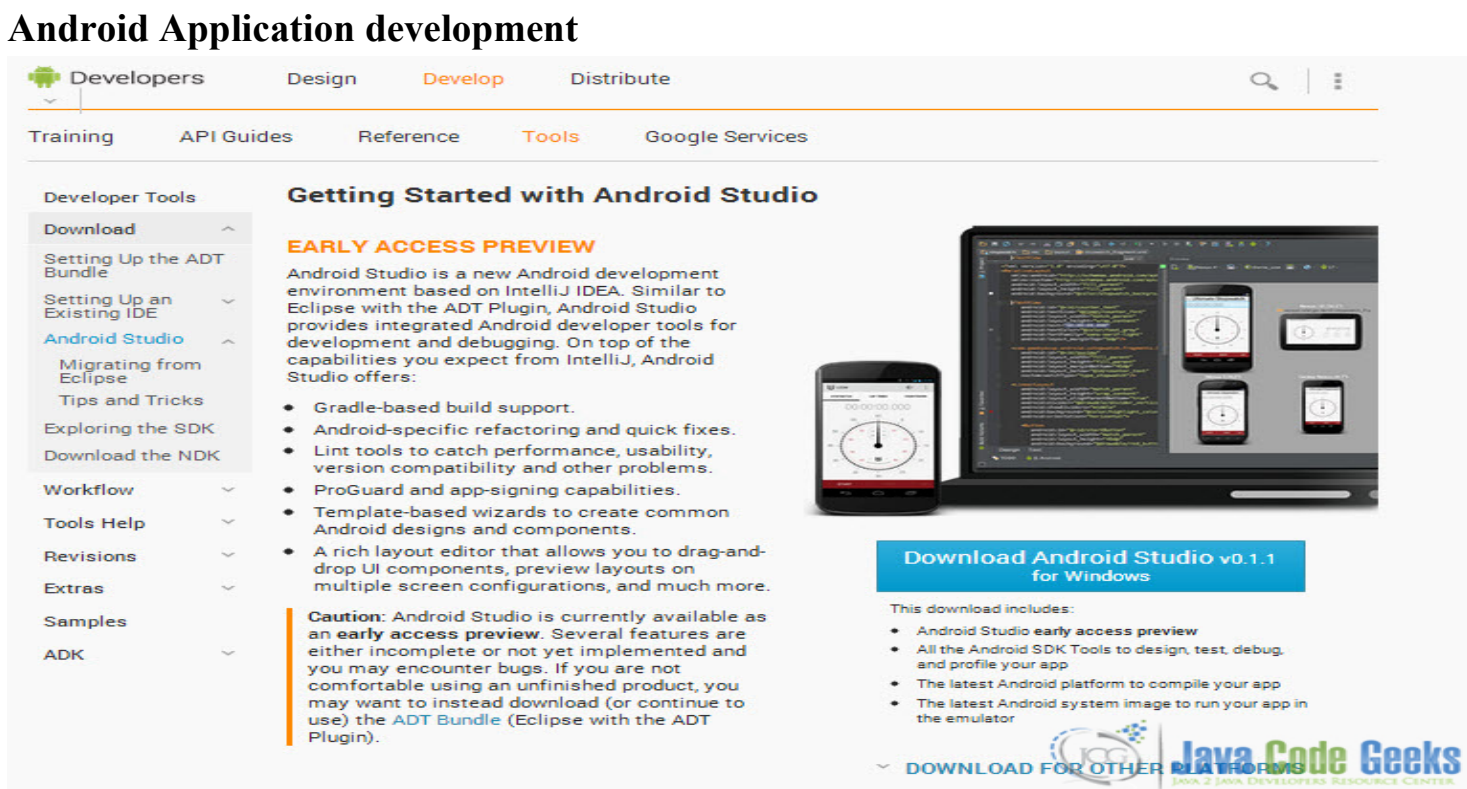

Fig 2.4 The following process was used for the development of the application.

\section{EXPERIMENT AND RESULT}

\subsection{GENERAL}

The Green Construct application was made in order to spread knowledge about the green building construction, the materials involved in the construction of a green building, benefits of each and every material which is used during the construction. Materials Efficiency is one of the elements of green building design and construction that contains the selection of green materials as the first step in developing sustainable buildings. In order to meet the requirements of the LEED rating system, architects need to consider whether the materials they chose consume less energy, have lower carbon emission features, contain recycled materials or regional reachability. More importantly, those considerations should be quantified in documentation to attain LEED certification.

In the LEED rating system, Materials and Resources (MR) account for almost 13\% possible points of the total possible points. And among the possible points of the LEED MR, building reuse can get 1 to 4 points but it is very difficult to get, especially for new construction. Except for building reuse, other requirements all ask for incorporating the project's LEED features, such as construction waste management, materials reuse, recycled content of materials, regional materials, rapidly renewable materials and certified wood. 


\subsection{Material/Product Selection Process}

Before understanding the process of material/product selection, it is important to know the entire process of a construction project. As indicates, any project of this kind mainly contains seven phases. In the first programming phase, the project has just started to be planned and the owner has only a general concept about the project. Also all potential participants have to decide whether to join in this project and get ready for bidding. In the second phase, schematic design, the project is handed to the architects and, with the assistance of the owner the architects finish the schematic design of the project. Then, in the third phase, the architects detail the design drawings and provide enough information needed for the construction phase. Afterwards, the architects are responsible for detailing all their works in documents, which is handed out to the contractors. Then, according to the documents, contractors prepare bids for their work and present them to the owner. Once a contractor is selected and is being awarded for the construction work the construction of the project begins. After the successful construction, the project can be occupied by the users.

All of the technical information of materials/products such as geometric properties, LEED features and testing results is collected in the first step. And learning technical information of different materials/products becomes crucial in this step. The second step involves confirmation of the technical information and more importantly compare different materials/products with the same functions. LCA tools can be very helpful in this step. The final selection often involves the use of individual criteria including the LEED rating system to make the final decision.

\subsection{GREEN BUILDING DOCUMENTATION PROCEDURE}

Electronic documentation is required for all prerequisites, each elective item submitted and all education and training components. Each document must be numbered according to the Section and Item Number (i.e. Prerequisite 1, Elective 3). Documentation must be limited to $10 \mathrm{MB}$ and 50 pages. Submit all documentation as one PDF file to greenbuilding@abc.org.

\subsection{Why Build Green?}

Buildings account for: 39 percent of total energy uses. 22 percent of the total water consumption. They consume 68 percent of total electricity and 38 percent of the carbon dioxide emissions.

Environmental benefits

- Enhance and protect biodiversity and ecosystems

- Improve air and water quality

- Reduce waste streams

- Conserve and restore natural resources

Economic benefits

- Reduce operating costs

- Create, expand, and shape markets for green product and services

- Improve occupant productivity

- Optimize life-cycle economic performance

Social benefits 
- Enhance occupant comfort and health

- Heighten aesthetic qualities

- Minimize strain on local infrastructure

- Improve overall quality of life.

\subsection{RESULTS}
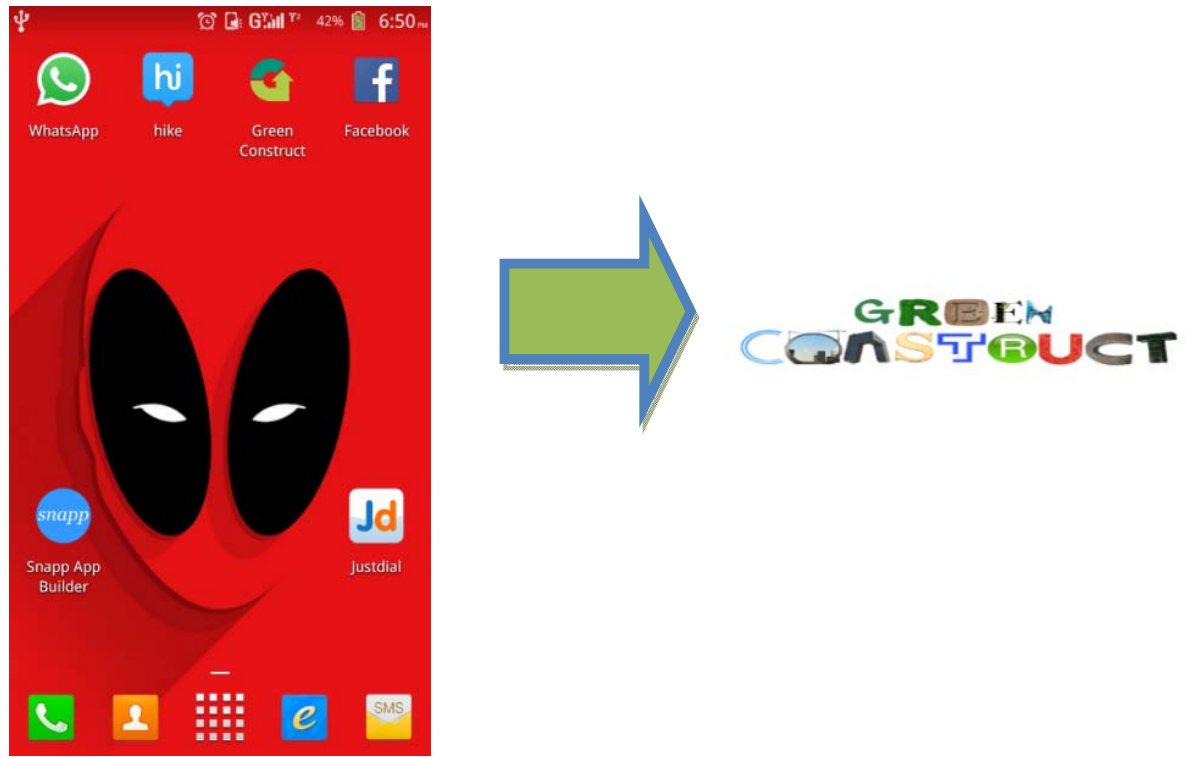

Fig. 3.5.1 App logo \& Splash Screen
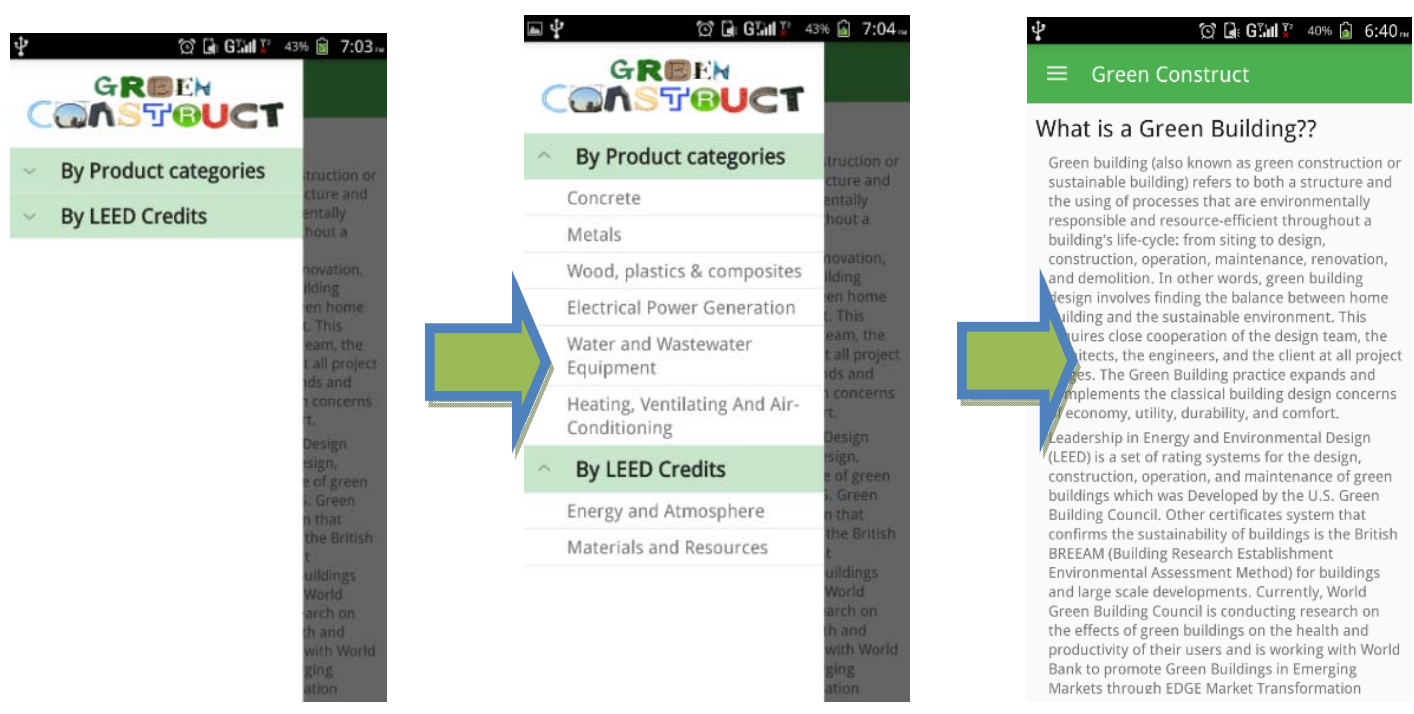

Fig. 3.5.2 View of the navigation bar in the application 

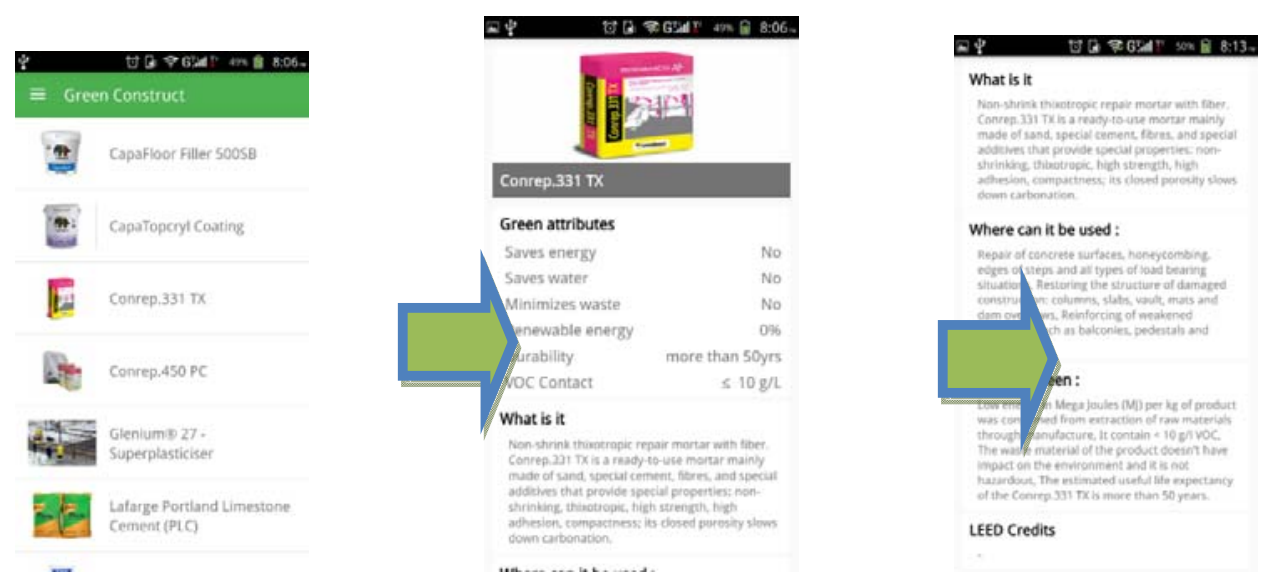

Fig. 5.3.3 Material list

\section{IV.CONCLUSION}

Initiatives shall be taken to educate the staffs, building occupants, visitors and the clients on the various sustainability measures that can be taken to create more environmental friendly energy efficient spaces. Housekeeping by biodegradable materials to address health, hygiene and well-being of staff make them eco-friendly. The building has been designed by En3 to showcase various green and sustainability measures and practices to ensure great amount of awareness is created by the buildings to promote green awareness to all the visitors and occupants \& spearhead the green movement in the state and the country.

"Green Buildings - Cheapest Way to Slow Global Warming"

The main aim of "GREEN CONSTRUCT APP" is to spread knowledge about green building, sustainable construction, benefits of green building materials and its environmental impacts through a mode of communication (SMARTPHONE) which is one of the best modes of communication. Through this application we are aiming to spread the highest knowledge to each and every individual and give them a simple access to the materials and data which they are not aware of.

\section{V.REFERENCES}

1. Fedriuzzi , Rick , (2009) "What LEED Measure, united states green building council”

2. Froeschle,L.M.(1999), "Environmental assessment and specification of green building materials"

3. Waidyaseara, K.G.A.S, and De Silva, M.L. (2013) "Comparative study of green building rating system in terms of water efficiency and conservation", department of green building economics, university of Moratuwa, Srilanka .

4. Yan ji and Stellios Plainits (2006): "Design for Sustainability". Beijing china architecture and building.

5. Simpsons, J.R (2008) "Energy and Buildings" Explain about residential energy use.

6. Green Contractor Certification Application, http://www.greenconstructionatwork.com/Tools_Resources/Green_Contractor_Certification/ Application.aspx, last accessed on (March 7, 2016)

7. Statista 2016

8. Android devices resolutions (March 2016) 